\title{
In the Public Interest? \\ Planning in the Peak District National Park
}

\author{
Christopher Maidment \\ Planning Policy and Conservation Team \\ Bassetlaw District Council
}

Submission for Planning Theory Special Issue on Planning and the Public Interest

\begin{abstract}
The recent history of the public interest is one of misappropriation. Practitioners have been found to value the concept but have struggled to articulate how it guides day-to-day planning practice. It has been used to portray a homogenous public, furthering the interests of the powerful at the expense of recognising social diversity, and leading to calls for the concept's abandonment (Sandercock, 1998). Yet this article starts from the argument that the public interest remains the justification that fundamentally underpins planning activities, in light of a continuing need to address collective concerns. To this end the article adopts the typology put forward by Campbell and Marshall (2002a; 2000), outlining different ways in which the public interest may practically be addressed. Alongside this Dewey's (1954) work is used to understand how the extent of the public may vary, leading to the use of scale as a way of recognising when different conceptions of the public interest might be practically drawn upon. Following this approach, the typology is brought together with scale, as a lens for understanding the extent of a public with a common interest, to form a framework for analysing practice. This framework is used to analyse how the interests of different publics are addressed in a case study of the Peak District, a national park in England. From the case conclusions are drawn around the need to pay greater attention to the extent of different publics with a common interest, and, in turn, how the interests of different publics can be reconciled.
\end{abstract}

Keywords: public interest, national park, planning, scale, England

\section{Introduction}

The starting point for this article is the view that the public interest "remains the pivot around which debates about the nature of planning and its purposes turn" (Campbell and Marshall, 2002a, p.181); the collective interest of the 'public' is the fundamental justification for planning activities. Yet, whilst this may address the question of 'why' undertake planning, it immediately leads to further questions of 'how', and 'for whom'? Who, and what, constitutes the public whose interests planning seeks to address? What role should participation play in addressing the interests of the public? 
The suspicion with which the public interest is regarded by contemporary planning theorists (Campbell and Marshall, 2002a) is well illustrated by Sandercock's (1998) rejection of the concept, following its use to oppress through homogenization; furthering the interests of dominant groups, whilst framing these as the interests of all groups. Sandercock does not reject the need to address group-based interests, but does contest the idea that these can be characterised as a singular public interest, instead favouring the pursuit of interests as they are irreducibly multiple in nature, characterised as 'togetherness in difference' (p.199, ibid). In terms of participation this leads to the need for the greater use of deliberative, or participatory, forms of democracy.

There are others who continue to believe that the concept of the public interest has value, particularly in a democratic system that inevitably remains partially dependent on representative democracy. This position might be summarised in Flathman's $(1966, p .13)$ assertion that, in the face of conflicting priorities, 'We are free to abandon the concept but if we do so we simply have to wrestle with the problems under some other heading.' The resulting conundrum is whether it is better to think in terms of multiple interests, to be addressed through a more participatory framework, or to continue to draw on a singular public interest as a concept that is familiar, but tarnished by its historical associations, in recognition that some interests cannot directly participate and will continue to rely on representative forms of democracy.

This is a conundrum that may be addressed through the use of scale, as a lens for understanding the extent of a public that shares a common interest, and, in turn, whether that interest can be practically addressed through participation. The article's aim is to thus explore how planning practices mediate differing understandings of what is in the public interest. It begins by exploring the conceptual and historical nature of the concept, both the arguments for its relevance, but also how tendencies to see the public as a homogenous body have led to its misuse. In particular, this discussion draws on different conceptualisations of the public interest and how they are related to debates around the role of participation in planning. This sets the scene for an empirical investigation of planning processes within the Peak District National Park, one of ten national parks in England, which is analysed to illustrate the tensions involved in mediating different interests as they are defined at different scales. Finally, some conclusions are drawn around the extent to which the case study might suggest whether different conceptualisations of public interest should be prioritised.

\section{The nature of the public interest}


To argue for the public interest as the fundamental justification for planning is typically understood as an argument that humans within a particular geographical area have a collective stake in how society operates, and that this stake can be expressed as a single voice. For Flathman (1966) acting in the public interest should represent a normative course of action, only called upon by elected representatives where they are acting impartially for their constituents, and accompanied by an explanation of the underlying rationale, in order to avoid obfuscation.

In turn it is necessary to define the group referred to when talking about the 'public'. However this is dependent on a number of factors. Healey $(2007$, p.15) comments that formal institutions of governance have traditionally been expected to pursue the public interest as the 'collective interest of the majority of citizens in a formal political and administrative jurisdiction, such as a nation, a region or a municipality'. At first sight this is an uncontroversial definition, one that fits well with the tendency of planning systems to be built around different institutional bodies, each of which has responsibility within a particular boundary. Equally it allows members of the public for whom planning is undertaken to be easily identified, providing a clear body of people whose interest is at stake, and who might reasonably be invited to participate in planning processes. There are, however, a number of reasons why such a definition cannot be accepted as normative.

In particular, such a conception assumes the 'public interest' comprises only the interests of an area's existing citizens, ignoring the impacts of planning activities on the environment, other species and future generations. Taking forward the interests of the majority may also be interpreted as licence to ignore the rights of minorities, raising questions about how appropriate interests to pursue are settled upon, and, in turn, whether members of the public can be assumed to know what is truly in their interest (Moroni, 2004)?

Furthermore a definition of the public interest that characterises space as discretely bounded is not helpful in addressing how planning activities must deal with conflicting interests at different scales, and cannot address ideas of place as relationally constructed, through the intersection of complex networks at multiple scales (Graham and Healey, 1999).

\section{A normative definition of the public}

Dewey's (1954, p.15-16) construction of the line between public and private is arguably useful in starting to address these inadequacies: 
The public consists of all those who are affected by the indirect consequences of transactions to such an extent that it is deemed necessary to have those consequences systematically cared for.

According to Dewey, if the consequences of a decision confine themselves to the parties directly involved in making that decision it is a private matter. However, when those consequences have an impact that reaches beyond those parties the decision becomes a public one. Drawing on this distinction between public and private brings into existence a public interest when the consequences of a decision go beyond those involved in making it. In turn the extent of the public is defined by the extent of the decision's consequences, a matter of scale.

Emphasising the usefulness of scale as a lens, Dewey considers it possible for people be too closely linked to need political organisation in order to address the consequences of a decision. Alternatively he considers it possible for people to be too isolated to share in a decision's consequences. The 'public', therefore, comes to be defined as a group with a collective interest in the consequences of decision-making, but without the ability to participate in it.

However, Dewey's definition relies upon the ability to agree upon where the consequences of a decision have effects beyond those directly involved, particularly if it is recognised that what constitutes a 'private' matter and what constitutes 'public' consequences are, both, socially constructed, and historically situated. Furthermore, Dewey's conceptualisation of the public is reliant upon conceiving of democracy as representative; a public only comes into existence when the consequences are indirect and therefore cannot be dealt with through the participation in the making of the decision by all of those affected.

\section{The public interest and the 'state'}

Dewey's definition is reliant upon the existence of a state-like construction, made up of people charged with systematically caring for these 'spillover' effects. However Dewey criticises the sovereign 'state' for being unresponsive and self-reinforcing, instead arguing for a multiplicity of models that respond to the circumstances in which they operate. Certainly the state's tendency to appropriate the ability to define what is in the public interest, in parallel with the aforementioned use of geographical boundaries to de-limit the public, can be characterised as a key contributor to the concept's declining fortunes.

Arguments for consigning the public interest to the history books have strong foundations in the imposition of rationally framed planning solutions by the state. Authors in the North American 
context have considered how the legitimacy of the concept has been undermined by its use to justify modernist urban interventions such as large scale social housing projects (Fainstein, 2010).

For Schön (1983) the high profile failure and subsequent demolition of these interrupted a working consensus about what constituted the public interest that had remained stable until the mid-1960s. This has been interpreted as prompting the formation of special interest groups, challenging the idea that universal values could be discerned in the face of diverse societal interests (Flathman, 1966; Davidoff, 1965).

Conversely this approach to the public interest has been described as experts working to rationally analyse problems from within the state, such that it becomes about the interests of the powerful, and their tendency to see a homogenous public, at the expense of recognising social diversity, or multiple publics, and leading to the marginalisation of less powerful groups (Sandercock, 1998). In particular the framing of what is in the public interest as a matter of technical-rational analysis, to be presented to elected representatives for their approval on behalf of the public, belies the extent to which 'experts' are reliant upon their values in making judgments (Schön, 1983; Davidoff, 1965). Reflecting this Flathman (1966) has concluded that the public interest can only ever be subjectively defined.

\section{The public interest in planning practice}

Similar difficulties with the concept's use have been recorded in the English context, in the day-today practices of planning. Whether employed in the public or private sector, anyone wishing to work as a planner in England is usually expected to hold membership of the Royal Town Planning Institute (RTPI), as the national professional body. Members commit to upholding the RTPI's Code of Conduct, which makes it the Institute's objective "...to advance the science and art of town planning for the benefit of the public" (p.1, RTPI, 2016). However, whilst planners have been able to draw comfort from this commitment (Campbell and Marshall, 2000), it is less clear that this is upheld through their practices.

In England the 1947 Town and Country Planning Act has generally been regarded as a seminal piece of legislation, giving form to a planning system that hasn't fundamentally changed since. This was set up as a twin-track system, with policy prepared at the municipal scale, and decisions made about particular development proposals with reference to this policy. The Act is identified as part of the post-World War Two welfare state, positioning the public interest as something to be looked after by the state, in the form of the local planning authority with responsibility for a bounded geographical area. Plans were presented to the public as complete, drawing upon representative 
democracy to claim legitimacy (Ward, 2004); echoing the North American experience, the public's interest in what planning should try to achieve would be looked after by their elected representatives, who would have ultimate power over planning decisions. However this left the public without any direct mechanism to participate in planning processes and it wasn't until the late 1960s that English plan-making processes were legally required to encourage public participation (CPPP, 1969). Meanwhile, lack of opportunity for the concerns of the public to be taken into account led to suspicion, at its deepest in the 1970s, that inappropriate deals were being made between local planning authorities and private developers (Booth, 2003).

A continued decline in trust in the contemporary context is driven by perceptions that planning activities continue to be technocratic in nature, and dominated by powerful interests (Tait, 2011; Swain and Tait, 2007). Equally planners are considered to know how to encourage the public to participate in planning, but not why they should encourage participation (Campbell and Marshall, 2002b). The English planning system has, simultaneously, been subject to regular legislative reforms, particularly since 2004. Whilst the system's twin-track nature survives, successive governments have tried to repurpose planning to pursue their own ends. In particular, reforms enacted by the 2010-2015 Conservative-Liberal Democrat Coalition Government include the introduction of the National Planning Policy Framework (NPPF, CLG, 2012), which sets a clear economic growth imperative for planning activities.

For Healey (2012) the consequences are that many people feel excluded and ignored, whilst the state responds to public concerns as they are overhyped by the media, rather than risk allowing public debate. This is echoed in the de-politicisation of planning issues, leading to the formalisation of policy solutions to issues such as climate change at a national level, without opportunity for citizens to meaningfully engage with debates about how they should be addressed (Owens and Cowell, 2011).

This can be partially attributed to a lack of clarity about how the public interest should be addressed. Surveying North American planners Howe (1994) found that practicing planners find the public interest, as about serving communities, to conflict with obligations to their employers. A similar lack of coherence has been evident in the English context; over time planners have found it difficult to know who they are obligated to and where public involvement should sit in planning activities (Campbell and Marshall, 2002b; 2000; Healey and Underwood, 1977). In the practice of making decisions about specific planning proposals, the public interest was suggested to be either about protecting public space or promoting economic growth, definitions that are not easily reconciled 
(Tait, 2011). Similarly, research in the Republic of Ireland suggests that planners found it difficult to define the concept, despite feeling that it acted as a guiding principle in their work (Fox-Rogers and Murphy, 2015). Such issues are consistent with the difficulty of identifying a singular public interest, whilst simultaneously recognising social diversity, and reconciling the existence of different publics at different scales.

\section{A typology of the Public Interest}

To address this incoherence it is useful to examine the different ways in which the public interest might be articulated. Campbell and Marshall (2002a; 2000) present a typology based on three contrasting ways of articulating what is in the public interest; the summative, the communicative and the common good, where the latter two definitions are arguably more normative in nature. $\mathrm{A}$ similar typology discussed by Alexander (2002) highlights the contrast between the concern of the summative and the communicative with the quality of the process (characterised by Alexander as a 'dialogic' approach), and the concern of the common good with pursuing particular outcomes (characterised by Alexander as a 'unitary' approach).

The summative model is concerned with the balance of collective opinion. Campbell and Marshall (2000) suggest that this approach has continued to thrive, expressed both through participation in the market, but also through participation in the election of politicians. It is a highly democratic conception of the public interest, but not one that is particularly collective in nature (Sorauf, 1957). Arguably more 'public' in nature is the conception of the public interest based on communicative, or dialogical, theories of planning. This approach places far greater emphasis on participatory decision-making; those who form the affected 'public' debate together how their concerns may be best addressed, with the aim of reaching a consensus (See for example Healey, 2006; Innes, 2004).

Many of those associated with communicative approaches would be uncomfortable being associated with the concept of the public interest. Equally communicative approaches are at odds with Dewey's (1954) definition of the public as too dispersed to address its own interests. However they arguably do significant work rehabilitating ideas of a deliberated collective interest, whilst positively accepting society's diversity, and addressing increasing dissatisfaction with representative democracy (Hay, 2007). Meanwhile the concern of such approaches with communication, as a way of overcoming unequal power relations, helps to address the public interest's association with imposition by the powerful. The remaining question is whether such an approach can effectively address multiple interests as they are defined at different scales. 
The common good is based on the idea that, whilst all members of the public have their own individual interests, they intrinsically share some fundamental values. The concern of the common good is with achieving these values, a matter of judgment, rather than ensuring that they are strongly shaped by participation. This is summarised in Fainstein's $(2000$, p.128) suggestion that 'political mobilization requires a goal to mobilize about.'

To draw on Dewey's (1954) definition it can be argued that the common good addresses issues that affect a public too large or diffuse to be resolved through participatory practices. Equally this addresses the criticism that a communicative approach conflates those who should be able to have say with those who will be affected; such a conflation is challenged by the potential for this to ignore the impacts of planning decisions on those aforementioned groups who cannot directly have a voice, particularly future generations and other species (Nussbaum, 2008). Climate change is a good example of this; addressing it draws on the value that a changed climate will adversely impact everyone and everything, including plant and animal life, but where its urgency prompts Owens and Cowell (2011, p.14) to ask 'How can we justify a deliberative role for planning when faced with the exacting goal of reducing greenhouse gas emissions to $80 \%$ below 1990 levels by 2050 ?'.

The consequence is that arguments can be made for the relevance of both normative conceptions of the public interest, not least in the way that each addresses a particular set of practical circumstances. These practicalities can be said to revolve around the scalar extent of the public, in terms of both time and geography. Some issues may have consequences that create a public spread across the globe and into the distant future, rendering a truly participatory approach practically difficult. Other issues may have short term, or geographically localised, impacts, arguably making it easier to bring the affected public together. Moreover, drawing on a relational understanding of place (Graham and Healey, 1999), planning decisions may have implications for multiple publics, each with a different scalar extent.

In this way, the normative approaches to articulating what is in the public interest outlined cohere with scale, as a lens for understanding the extent of a public with a common interest, to form a framework for analysing practice. This leads to the examination of a case study, the Peak District National Park, to analyse how different ideas about what is in the public interest, as they are articulated at different geographical scales, and over different timescales, are mediated through planning practices, as they draw on different conceptualisations of the public interest.

\section{A Case Study: The Peak District National Park}


The Peak District National Park is an area of hilly countryside located in the north of England, tightly surrounded by the densely populated conurbations of Manchester to the west, Sheffield to the east and Leeds to the north. In the international context, it is not the type of wilderness, bereft of human activity, that might be associated with the African or American imaginations of a national park; it is protected for its perceived landscape value but is also home to 38,000 people, as well as significant mining, quarrying and farming activities, activities that have shaped this landscape since the days of the Roman Empire.

The Peak District was designated as a national park under the 1949 National Parks and Access to the Countryside Act, on account of its perceived landscape beauty and opportunities for open air recreation for the public, both inside and outside of the park. As a national park it has associated with it a set of statutory purposes around conserving the landscape, as set out by the 1949 Act.

These statutory purposes, and the distinctive governance arrangements that accompany them, set the Park apart from a typical English local planning authority. For this reason the Park was chosen as the subject of doctoral fieldwork, with the stated aim of exploring what versions of the public interest are present in the processes of making spatial plans, drawing on the typology put forward by Campbell and Marshall (2002a; 2000). In order to develop an in-depth understanding of how the public interest is articulated through planning practices, whilst accounting for the context specific nature of planning, a case study methodology was chosen.

The core data was collected through a series of semi-structured interviews, contextualised by data collected through observation and document analysis. In total twenty three interviews were conducted, taking in a range of groups. These included planners, authority directors, campaign group representatives, national membership organisations, and political representatives of the National Park Authority, and the parishes and towns that make up the Park.

Two further points about the methodology are worth relating. The first is that none of the interview questions specifically addressed the public interest. Other authors (See for example Fox- Rogers and Murphy, 2015; Howe, 1994) have shown how planners struggle to articulate the meaning of the concept. Instead it was felt to be more helpful to consider how the practices related by different interviewees adhered to different conceptualisations of the public interest. This required an additional layer of interpretation, using the framework outlined above to identify, both, where the interests of different publics were being addressed, and where these interests were being articulated in different ways. 
The second is that observations were made from a position of being embedded within the team of planners responsible for plan-making in the Park; one or two days a week were spent with the team over the course of the fieldwork, undertaking small pieces of work for them. The quotes presented here are intended to tell the story of how the tensions between different 'publics' are reflected in everyday planning practices in the Park.

\section{An authority organised around tension}

From the outset a series of different interests can be identified; those of people living inside the park, and of visitors to the Park, in turn contrasting with the intrinsic natural beauty of the landscape, and the economic value of the resources underneath the Park's surface. To put this in terms of the Deweyan public it can be suggested that these different interests create different publics, each with contrasting interests to be cared for; the case study aims to highlight both how each interest is articulated, and, in turn, how planning activities mediate between them whilst drawing on particular conceptions of the public interest.

The institution in which these competing tensions converge is the Peak District National Park Authority, which has the explicit purpose of upholding the Park's statutory purposes. The Authority's structure is generally typical of English local government; its work is undertaken by paid officers, governed by representatives, generally known as 'members'. Where it first differs from most local authorities, however, is in having a far narrower range of responsibilities: the Park's boundary takes in parts of eleven local authorities, who continue to provide most services associated with English local government, for example refuse collection and highways maintenance, in their constituent parts of the park. However the Peak Park Authority appropriates from these municipalities responsibility for services that are deemed to significantly impact on the statutory purposes: namely planning, in the sense of both making spatial plans and making decisions on individual applications for planning permission, conservation, and tourism.

As a consequence of the 1949 Act it can be suggested that the Park's statutory purposes give planning processes in the park a clear objective, in line with conceiving of the public interest as the common good. In the intervening decades this has been reinforced by the 1974 Sandford Review, which sought to clarify how different interests should be prioritised by the authority, in particular the extent to which nature conservation should be prioritised over recreation. This led to the Sandford Principle, transposed into statute with the following wording: 
...if it appears that there is a conflict between those purposes, shall attach greater weight to the purpose of conserving and enhancing the natural beauty, wildlife and cultural heritage of the area comprised in the National Park.

(Environment Act, 1995)

Historically, quarrying of the Peak District's extensive mineral resources has been widespread, facilitated by permissions given that pre-date its designation as a national park. However a standing objective for the authority is a reduction in quarrying activities, with a member of the Authority noting a steady decline, managed pragmatically, with new permissions occasionally given '...when it seems sensible to do it as a quid pro quo...for giving up permissions which we feel might be more dangerous to the landscape than the new one that they're seeking.' To a certain extent this removes the characterisation of the landscape as an economic resource from the set of contrasting interests identified. However the management of the remaining conflicts is framed by how the historically and structurally embedded value of protecting landscape beauty competes with the desire of the local population to more actively voice their own interests.

The tension between competing human interests was succinctly characterised by one of the authority's policy planners, in the notion that the Peak District is '...protected for the interests of people who don't live there', leading to '....an area where the decision-making is largely based on protecting something that's valued by the rest of the country, where those values might disadvantage the local people...' Another policy team member made the same point more bluntly:

...38,000 people live here but actually it's not their interest that we're planning this area for exclusively. You know, their interest is important to us but it's, there's millions of other people coming here to enjoy this area...

Following from the statutory purposes and principles that underpin the Park's designation one of the Authority's planning directors asserted that '...we have a statutory basis to what we do which other planning authorities don't... While you're working for a national park you should never have any uncertainty about what your job is...' Implicit to this is the suggestion that officers should be able to draw on the rationale for designating the area a national park to provide a clear sense of direction when making judgments between competing interests. However this sense of purpose has become less clear, both in how it has been challenged by aforementioned central government policy reforms, and in changes to the arrangement of the Authority's representative membership. These changes have had a significant impact on how planning processes mediate between the nationally, historically prescribed common good put forward through the Park's statutory purposes and the 
interests of the Park's residents, as they have been put forward in a more participatory manner; it is to the first of these that this paper now turns.

\section{The competing influences of historical purpose and contemporary reforms}

The role of planning, as a mechanism for protecting the Park's landscape, was emphasised by one of the Authority's planning directors:

Clearly planning is the most important function of the authority...If we get the planning wrong the rest of it is, I wouldn't say irrelevant, it's certainly heavily compromised because if we get planning decisions wrong our landscape protection goes.

This prioritisation of landscape protection has resulted in a planning strategy that rules out any major development. This means it is exempted from the pressures on most English local authorities, who are required by central government to plan for new housing that responds to long term demographic projections of population growth. Instead population growth in the Park is controlled through limits to development, a principle that has been reinforced through multiple cycles of planmaking.

A particular effect of this has been to amplify the scrutiny of small scale proposed developments, on the basis that even small changes can be suggested to impact on the integrity of the landscape's beauty. As a result decisions about small scale developments, cases that would often be delegated to officers at other local authorities, for example a single house or the placement of solar panels, are debated by the authority's planning committee, made up of a subset of the Authority's members.

The decisions made by planning committee are given more detailed consideration in the next section. However it useful to note here that the amplified impact of smaller changes is somewhat at odds with the contemporary context for planning in England. The aforementioned introduction of the NPPF, with its focus on economic efficiency, can be characterised as setting a 'common good' for the whole country, drawing on the assumption that new development is good unless proven otherwise. However the NPPF's introduction is considered by planners working for the Park Authority to have led to the national park concept being diminished, leading to misunderstandings (aired during public consultation on a new plan) that the Park was also expected to meet demographic-driven house building targets.

Consequently the six decade old rationale for the park, based on the landscape's intrinsic value, must compete with this more recent economic growth narrative. This illustrates a tension between 
two conceptions of what is felt to be in the public interest, but where both conceptions are defined at the national scale. A national interest in economic growth, intended to be pursued across the whole country, competes with a national interest in protecting what are considered to be important landscapes, but where this applies to only certain parts of the country.

More recent reforms introduced by central government have widened the permitted development regime $^{1}$, allowing (for example) the conversion of office buildings to residential use and the conversion of farm buildings to other uses including dwellings, without the need for planning permission. As a result, a range of developments that were previously deemed to have a sufficiently widespread impact to be debated as a matter of 'public interest' may now proceed as matters for private decision-making.

On the basis of the amplified effect of such developments in a protected landscape the Peak Park Authority applied for an exemption from the changes. That they were unsuccessful proved a source of irritation for authority officers and members alike, provoking frustration that the Park's difference from other parts of England was not well understood by the Conservative-led government, particularly in comparison to the previous Labour government. This can be interpreted as central government treating England as a homogenous whole when setting policy that embodies a particular view of what is in the public interest. The response of one of the Park's planning directors was to suggest that the Authority needed to articulate why it should be treated differently:

...we need to get national parks back up the agenda and get the government to understand the consequences of what might appear to them to be relatively minor changes in planning legislation...how significant they can be in very sensitive landscapes like national parks.

Senior officers at the Authority suggested that it was necessary for English national parks to speak to government with a single, collective voice. This draws on a common good understanding of the public interest in assuming that there is still a widely shared interest in the protection of national parks, without necessarily consulting other groups. Moreover, citing the contemporary context in which the pursuit of economic growth is strongly embodied in national policy, and the need for strong counter arguments for why this should be given less weight, the same officers articulated the need to be tactical. The result is a reversal of the situation where national parks were originally defined and given purpose at the national scale, to one where the parks themselves feel the need to promote those purposes back to central government. However, this assumes that the Park's

\footnotetext{
${ }^{1}$ The permitted development regime sets out the types and scale of development that may go ahead without the need for planning permission.
} 
conservation purposes should continue to override other interests, a judgment that does not command universal assent, particularly when the needs of local residents are considered.

\section{Development that meets local needs}

Considering how the assumptions around the importance of landscape protection were reflected in practice, one of the Authority's policy planners asserted that the values embodied by the Park's conservation purposes were strongly shared in the abstract, but were being challenged at the point where decisions were made to either permit or refuse development:

People are happy that big open market estates aren't going to happen, that big windfarms aren't going to happen and that we are essentially about landscape; I think at that big level there's a lot of common purpose but, at the minute, there's a lot of the real intent of core bits of policy that...we're finding it quite difficult to...get that understanding of what we're trying to achieve.

In relation to the varied set of interests identified in the introduction to the Park, the picture that emerges is of coalescence around protecting the park's landscape beauty up to a point. The same interviewee commented on how the Authority's policies frame new development as about meeting the needs of existing residents, contextualised by the aforementioned constraints on population growth in the Park:

...we would say policies are there to support local communities but it needs to be there in a sustainable manner, so it supports communities in the long run, not just this individual personal need that might be transient or short term but actually you're leaving a legacy of development that should support the community in the long run...

The comments suggest how the passage of time creates a public that is more extensive than the area's current residents, and should therefore override the needs of existing residents. In turn this highlights how even geographically localised issues can have consequences of a significant scale in other ways.

An example of the tension hinted at in these comments is the creation of a Neighbourhood Plan by one village in order to resist the redevelopment of an industrial site for housing. The Peak Park Authority saw an opportunity for a larger, open-market development that would deliver several affordable houses, but the local community saw a development that would significantly increase the village's size, without meeting local needs. Another example, cited by a town councillor, involved barriers to the conversion of a building, listed for its historical value, into affordable 
housing, because the required changes were considered to affect the integrity of the Park's character. However permission was given for lesser changes, which would allow the building to be converted into holiday accommodation, not a form a development that addresses local needs, but one that, instead, addresses the Park's defined purpose as a destination for visitors.

Other interviewees from around the Park note that it is difficult for people to afford to both live and work there, leading to significant commuting in both directions. The same town councillor cited the example of a very well regarded school, which struggled to recruit teachers because the Park was deemed an expensive place to live. Such examples contribute to the frustration expressed by members of a pressure group called Peak Park Watch, set up with the aim of highlighting concerns with the Park's governance:

People, jobs, everything else come second and that's terrible.

Whilst far from universal, such views begin to suggest how the interests of residents can be seen to conflict with the conservation purposes of the Park. The widespread nature of such views, amongst a variety of groups unable to make decisions directly, suggests the need for other mechanisms through which more local interests may be taken into account.

\section{The changing democratic nature of the Park}

In contrast with a typical English local authority, where political members are elected by residents within each authority's boundary, none of the Peak Park Authority's thirty members are directly elected by the Park's residents. Instead they are drawn from three groups. Sixteen members are appointed to the Peak Park Authority by the eleven local authorities that make up part of the park, drawn from each authority's elected membership. The remaining fourteen members are appointed by the Secretary of State with responsibility for England's national parks, on behalf of national government. Eight of this subset are appointed for their skills and expertise in the conservation purposes of the park, hereafter referred to as 'Secretary of State members', whilst the remaining six are 'parish members', appointed to represent parishes within the park².

This distinctive form of governance reflects the different interests that can be identified within the Park. Crudely, local authority members represent the interests of the local residents who elect

\footnotetext{
2 Parish council members are elected when there are more candidates than positions. Where insufficient members are elected to fill a parish council's seats, the remaining seats may be filled by co-opting members onto the council. Members appointed for their skills and expertise apply for vacancies as they are publicized by central government, and are appointed by the Secretary of State for Environment, Food and Rural Affairs. Current members of the Peak Park Authority appointed in this way have backgrounds in ecology, landscape management and local government, amongst others.
} 
them, both within and just outside the Park, and parish members the residents of parishes within the Park. In contrast, Secretary of State members, appointed for their skills and expertise, represent the historically and nationally defined conservation purposes of the Park. The resulting mix was reflected on by a Secretary of State member:

So we've each got our proper justification for being there and it's a very useful and helpful mix...l actually believe without those national members, chosen nationally, because the other people are all chosen locally, I mean we actually kind of embody some sense of this is a national park, not just a local park for local people.

This reflects the idea that the Park's conservation is in the interest of a public that exists at the national scale, taking in England's population as a whole. Yet, in practice, there is no democratic mechanism by which Secretary of State members are accountable to this 'public', such that it is within each member's discretion to judge how this interest is best served. This is consistent with the suggestion that the Park's conservation embodies a common good conception of the public interest. In contrast one of the Authority's parish members noted that they would need to be re-elected by the residents of their parish in order to continue serving on the Park Authority:

So we are responsible to our community and elected by our community. And those of us who are parish members are elected from the community within the park...so we have a big responsibility for the people we serve as well as the park we protect...

Similarly local authority members must be re-elected periodically by the residents that they represent.

Democratic responsibility to a defined group of people brings into play a summative conception of the public interest; in turn, being responsive to the views of people allows the possibility of defining the public interest in a more participatory, if not truly deliberative, manner. Consequently the arrangement of the Authority's membership results in representation being more directly democratic at local scales: parish members are elected from within the Park; local authority members are elected by their constituents but may not necessarily represent wards within the Park; Secretary of State members, representing the public on a national scale, are not elected. In response, some groups argue that all of the Authority's members should be elected by the Park's residents, and therefore more accountable to them, in line with a typical English local authority. However, whether such a move is appropriate is dependent on the extent to which representative modes of democracy can account for the multiple interests identified. 
In particular this raises questions about how elected representatives can be expected to be responsive to those interests who cannot be involved in electing them, for example the nationally defined interests identified. Evidence for this can be seen in historic changes to the Authority's membership structure, which have altered the interests taken into account in decision making, with a consequent impact on the extent to which decision-making is either representative or participatory in nature.

The inclusion of parish members is the result of changes to the Authority's membership in the late 1990s. Prior to this, the membership was split evenly, between those appointed by local authorities, and those appointed to represent national interests, a situation reflected on by one of the Park's planning directors:

...the balance in the debating chamber was often quite well balanced between all those interests... which tend to be brought into the room through Secretary of State appointments and their skills and backgrounds, and the local issues which tend to be brought in by the local politicians.

The changes reduced the number of Secretary of State members appointed for their expertise, replacing them with the parish members. Consequently three quarters of the membership now represent what might be conceived of as 'local' interests, where 'local' means within, or geographically proximate to the park. More than one interviewee noted that this has had a significant impact on decisions made by the Authority's planning committee, particularly on the interests prioritised in decision-making, impacting on how the public interest is conceived of. It is therefore useful to relate how decisions have been made in the Park under the current membership structure.

\section{The changing nature of planning decisions in the Park}

Drawing on the confidence that officers have about the Park's purposes one of the Authority's policy planners suggested that:

...we'd like to hope that when members arrive at the authority they can leave the baggage of their district and counties behind and that, when they come here, they're switching and they have a slightly different focus.

This hope is reflected in a request from the members appointed by local authorities, for a document, setting out the differences in policy inside and outside of the Park. Even though three quarters of the Park's membership are elected to make political decisions on behalf of constituencies, such 
comments embody a view that members should uphold the Park's statutory purposes, rather than seeing these as a matter of political choice. However, the same interviewee expressed disappointment that some members did not appear to appreciate how the Park was different in policy terms to the areas outside of it. This tension sets the context for examining how planning decisions are made in the Park, particularly whether they emphasise the public interest as it is conceived of more locally, or the nationally defined conservation purposes of the Park, potentially to the detriment of everyday quality of life for residents.

Comments made by of one of the planning directors suggest that the confidence expressed by officers in the Park's statutory purposes has led to problems, leading to changes in how officers write reports for the Authority's planning committee, which recommend whether proposals should be refused or approved:

They mustn't write reports that are so one-sided that members don't have faith in it...if you give the impression that every time you recommend refusal that the national park will end if this is approved, it's a bit like crying wolf; people stop believing in you...My approach has been to say to members 'if we are saying you really really shouldn't be approving this you've got to believe us because when we think it's marginal we'll tell you'.

The authority has come under fire from the pressure group Peak Park Watch, who have identified multiple instances where the authority have made decisions that are perceived to have inappropriately favoured or disfavoured certain groups, exacerbated by accusations that members are bullied by authority officers. As a result it has been suggested that planning powers should be returned to the district authorities that make up the Park, who are considered to be more approachable by members of the public. It is not possible to examine the validity of these claims here. However such claims do correlate, somewhat, with the extent to which officers are characterised as having a better understanding of the Park's purposes than most members, a sentiment echoed by one of the Authority's planning directors in relation to decisions about particular planning applications:

...in recent years I've seen far more examples where the officers have found the policy balance as a National Park Authority but the membership have gone for different balance because of their local messages.

This changing balance has been particularly visible in planning committee meetings, as a key setting in which tensions between the interests of different publics are mediated. In this setting the 
changed balance of the membership was suggested, by another planning director, to have a tangible impact on decision making:

...twenty years ago that decision in (Village Name) probably would have been a clear cut refusal because we'd have a strong enough block of Secretary of State members who weren't thinking about local politics.

It can be argued that this illustrates a shift in how the public interest is articulated, suggested by one of the directors to have resulted from parish and local authority members having '...high regard for what's been said to them locally and sometimes that can bring them into conflict with national park purposes, because those purposes are national purposes'. In turn, an undertone of frustration can be detected amongst the Authority's planners, around the weight given to local considerations, with a senior policy planner suggesting that members '...go straight to the details...and miss the point of principle...', commenting that 'it feels frustrating at the minute that there are cases that are going contrary to officer recommendation and therefore contrary to policy'.

To this end it is worth noting the minor restructuring of decision-making that allows such decisions to stand. Previously, decisions deemed contrary to policy could be referred, by the Authority's chief planning officer, to a meeting of the full membership for ratification. Following changes voted for by a majority of the membership such deferrals are now to the following month's planning committee, allowing members to reflect on whether the decision should be made contrary to policy. Ultimately, however, the power of ratification now lies with the same members involved in making the initial decision.

The implication is that because all 'local' members are elected, they must inevitably be thinking about being re-elected. Particularly members of the public exercising their speaking rights at these meetings are felt to have an overly strong influence on decision-making, with the same planner noting:

...as soon as you get in the room in front of some passionate, impassioned local person, hear that story and quite easily turn away from policy.

Indeed, the influence of applicants' use of public speaking rights on the dynamics of planning committee meetings was strongly apparent during observation. As such, these comments reinforce the tension between the Park's conservation purposes and the everyday lives of local residents. However, if this trend is seen more positively, as a desire to serve local communities, it is apparent 
in a number of recent decisions made by the Authority's planning committee that have departed from the officer recommendations, in favour of permitting what is wanted by local residents.

Supporting this perspective, a parish member suggested that their day-to-day knowledge of living in the Park left them well placed to decide where policy should be put aside. Particularly they felt that this knowledge allowed members to make decisions in a far more nuanced manner, drawing particular comparisons with the undifferentiated policy stance of central government:

...we have to make sure we don't put the wrong obstacles in their way...if we can flex the policy because we think actually it is being too constraining then we should, but that should be up to us, not up to somebody in Whitehall, behind a desk, saying that we've got to.

The result has been the approval of a number of houses that meet the needs of people with a local connection, despite being at odds with policy, and therefore against officer recommendations. In terms of their design and location these may be perceived as having a negative impact on the Park's landscape, but will positively contribute to meeting local needs.

\section{Mediating between different conceptions of the public interest}

The planning committee meetings bring into one arena the two dominant definitions of the public interest apparent in the Park's planning practices, both its statutory purposes as they have been defined at a national scale, and the needs of its residents as they have been defined more locally. The decisions made by the committee can therefore be said to represent a judgment about how they are reconciled. The aim of this analysis is to examine more closely how these competing definitions adhere to particular conceptions of the public interest, in order to draw some conclusions around the use of the concept.

The statutory purposes of the Park characterise the public interest as a singular common good, as it has been historically defined at the national scale. Senior officers and Secretary of State appointed members envision a gentle evolution for the Park that protects its landscape, translated into planning policies that set detailed criteria for achieving this, and reinforced through successive planmaking cycles. Such an attitude is paternalistic, suggesting what is best for the Park's residents without allowing them much influence over policy. This is particularly apparent in the mindset of officers, who frame their views as about what is best for communities in the long term. It is also evident in the implicit suggestion that officers understand the purposes of the Park better than the Authority's members, particularly the local elected ones. 
There is a clear argument for accepting this paternalistic approach, coming from its basis in the Sandford Principle, prioritising landscape protection. Following Dewey's (1954) formulation it can be argued that these intrinsic values encompass a wider conception of the public than just those groups and individuals living within the Park. Instead it is a public that is specified in abstract, homogenous terms by the Park's purposes, which extends to most of England's population, and further, if more global movements with an interest in protecting the environment, or future generations who might wish to enjoy the Park, are included. If one draws on Nussbaum's (2008) idea that the public includes those interests specifically bound up in the environment itself, i.e. the flora and fauna that cannot actively voice their own interests, this could be extended still further. In this sense it is a public created by the assumption of shared values, but with arguably few mechanisms for testing these values directly, highlighting the limitations of a conception of the public interest based solely on participation.

Concurrently, the principles underpinning the Peak District's national park designation have been rendered abstract by the passage of sixty years. The Authority wishes to promote these purposes back to central government, but they must compete for influence with the principles that define the contemporary context; the national policy context for English planning is increasingly influenced by neoliberal attitudes to economic growth, an arguably less laudable value, but one reinforced in an equally paternalistic manner. The lack of nuance in the application of the NPPF (CLG, 2012) and reformed permitted development rights show how these initiatives are being imposed in a rather blunt manner, removing any possibility to consider the wider implications of certain decisions. In turn this echoes historical tendencies to impose what is in the public interest on a homogenous public, assumed to be created by an interest in economic growth.

A concern with pursuing a nationally defined common good is also problematic in the extent to which it constrains day-to-day life in the park. Officers may feel comfortable making a clear judgment that wider conceptions of the public must take precedent over the needs of the Park's residents, but this is far from universally accepted. Particularly, whilst Secretary of State members may accept this approach, other members clearly do not. Equally other interests, from both inside and outside the Park, express frustration at the lack of freedom accorded to those who live and work in the Peak District.

In contrast the Authority's planners are concerned about the lack of understanding amongst local members of how small changes can impact on the Park's landscape. Yet local members are also those who may be characterised as creating space in which the Park's residents can have a more 
direct influence on development, through participation in planning committee meetings. Beyond allowing public speaking rights this setting makes little concession to a more participatory approach to planning activities, and does little to address a power relationship that favours officers and members. However, the aforementioned changes to the authority's governance appear to have been effective in making the authority more accountable to local residents.

There are a growing number of instances where residents have been able to persuade members to overturn officer recommendations, by making a clear and passionate case for fulfilling their own needs, often by also gaining the support of other groups such as the local parish council. This characterises the Authority's political members as those best placed to judge between the long term, protectionist emphasis in policy and the needs of local people. In this sense it is the members who mediate between nationally defined and more locally defined understandings of what is in the public interest, between representative and more participatory modes of democracy. However the tendency for Secretary of State members to side with the protection of the Park, whilst locally elected members side with local interests, ensures that decisions favouring residents result from a majority vote, as opposed to reaching a consensus. In turn this can be suggested to define the scale of the public whose interest is prioritised, somewhat at the expense of publics defined at other scales. Moreover the practical arrangements of the planning committee also serve to highlight the ability of local groups to put their interests forward in a persuasive way, an ability not afforded to interests who cannot directly participate.

\section{Conclusions}

This article set out with the aim of examining some key tensions in the use of the concept of the public interest: its continued use as a justification for planning activities despite its associations with imposition by the powerful; its articulation at multiple scales, leading to conflicting interests; and its association with both representative and participatory modes of democracy, and their associated modes of decision-making. The Peak District National Park illustrates how decision-making attempts to reconcile these tensions, bringing together different ideas of what is in the public interest as they are articulated at different scales, through different modes of democracy, in a single arena.

It is arguable that the broad coalescence around the Park's statutory purposes means that decisions to permit small scale developments, by overturning officer recommendations, do little to challenge these purposes, but work broadly within them to improve day-to-day life for the Park's residents. To this end the case provides some signposts as to how the principles of landscape protection, principles that serve an abstract, singular public, whose interests cannot be fully addressed through 
participation, can be reconciled with the interests of multiple, localised publics, who can more practically participate in defining how their interests might be addressed.

Campbell and Marshall (2000) highlighted a need to revive ideas of the common good and this is imperative in an era where issues such as climate change must be addressed, issues that create a public global in scale. However, the case illustrates that conceiving of the public interest in the singular is insufficient, but that planning activities must instead address multiple public interests. Drawing on Dewey's (1954) work greater attention needs to be paid to the extent of these different publics. In turn Campbell and Marshall's (2002a; 2000) typology provides the practical tools for addressing the interests of different publics, depending on the extent to which they may directly participate in planning activities.

Drawing on this approach, it can be suggested that more participatory, localised definitions of the public interest can be accommodated within a clear conception of what constitutes the common good, as shared by a broader, more abstract conception of the public, providing a normative direction for how planning activities should take into account the public interest. This must address past tendencies to impose by starting from inclusive deliberation about the principles that planning activities should aim to uphold, that makes space to consider how the interests of those who cannot participate are being addressed. As such, this is not about extending representative democracy, but is about deliberative processes that bring multiple public interests into a single dialogue, and that include mechanisms for judging whether these broader principles are being upheld.

Ultimately there is a need to address the public interest in a far more nuanced manner. The concluding argument is not for either a singular, or a dialogical approach to the public interest, but is that planning must pay greater attention to who, and what, is included in the multiple publics, whose interests it must address.

\section{Acknowledgements}

The author would like to thank Malcolm Tait, Kiera Chapman and three anonymous referees for their extremely valuable comments on previous versions of this article. Thanks must also go to all of those who contributed to the fieldwork, without whom this article would not have been possible to write.

\section{References}


Alexander E. 2002. The Public Interest in Planning: From Legitimation to Substantive Plan Evaluation. Planning Theory. 1, p.226-249.

Booth P. 2003. Planning By Consent: The Origins and Nature of British Development Control. London: Routledge.

Campbell H. and Marshall R. 2000. Moral Obligations, Planning and the Public Interest: A Commentary on Current British Practice. Environment and Planning B. 27.2, p.297-312.

Campbell H. and Marshall R. 2002a. Utilitarianism's Bad Breath? A Re-evaluation of the Public Interest Justification for Planning, Planning Theory, 1(2), p. 163-187.

Campbell H. and Marshall R. 2002b. Values and Professional Identities in Planning Practice, p.93109 in Allmendinger P. and Tewdr-Jones M. Eds. Planning Futures: New Directions for Planning Theory. London: Routledge.

CLG (Communities and Local Government). 2012. National Planning Policy Framework. London: Department for Communities and Local Government.

CPPP (Committee on Public Participation in Planning) 1969. People and Planning: Report of the Committee on Public Participation in Planning. London: Her Majesty's Stationery Office.

Davidoff P. 1965. Advocacy and Pluralism in Planning. Journal of the American Institute of Planners. 31.6, p.331-338.

Dewey J. 1954. The Public and Its Problems. Athens: Ohio University Press.

Environment Act 1995, Chapter 25. London: The Stationery Office.

Fainstein S. 2010. The Just City. London: Cornell University Press.

Fainstein S. 2000. New Directions in Planning Theory. Urban Affairs Review, 35.4, p.451-478.

Flathman R. 1966. The Public Interest. New York: John Wiley \& Sons.

Graham S. and Healey P. 1999. Relational concepts of space and place: Issues for planning theory and practice. European Planning Studies, 7.5, p.623-646.

Hay C. 2007. Why We Hate Politics. Cambridge: Polity Press.

Healey P. 2006. Collaborative planning: shaping places in fragmented societies. Basingstoke: Palgrave Macmillan.

Healey P. 2007. Urban Complexity and Spatial Strategies: Towards a Relational Planning for Our Times. London: Routledge. 
Healey P. 2012. Re-enchanting Democracy as a Mode of Governance. Critical Policy Studies. 6.1, p.19-39.

Healey P. and Underwood J. 1977. Conclusions: Current Dilemmas for Planning and Planners in the London Boroughs, p.116-122 in Healey P. and Underwood J. Eds. The Organisation and Work of Planning Departments in the London Boroughs. London: Centre for Environmental Studies.

Howe E. 1994. Acting on Ethics in City Planning. New Brunswick: Centre for Urban Policy Research. Innes J. 2004. Consensus Building: Clarifications for the Critics. Planning Theory. 3 (1), p.5-20.

Moroni S. 2004. Towards a Reconstruction of the Public Interest Criterion. Planning Theory, 3.2, p.151-171.

Fox-Rogers L. and Murphy E. 2015. Perceptions of the Common Good in Planning. Cities, 42, p.231241.

Nussbaum M. 2008. Martha Nussbaum - Part 1 - The Social Contract. Available at: http://www.abc.net.au/radionational/programs/philosopherszone/martha-nussbaum--part-1---the-social-contract/3174420 (Last Accessed: 27th May 2016).

Owens S. and Cowell R. 2011. Land and Limits: Interpreting Sustainability in the Planning Process: Second Edition. London: Routledge.

RTPI (Royal Town Planning Institute) 2016. Code of Professional Conduct: As last amended by the Board of Trustee: Effective from 10 February 2016. London: Royal Town Planning Institute

Sandercock L. 1998. Towards Cosmopolis. Chichester: John Wiley and Sons.

Schön D. 1983. The Reflective Practitioner. London: Temple Smith.

Sorauf F. 1957. The Public Interest Reconsidered. The Journal of Politics, 19.4, p.616-639.

Swain C. and Tait M. 2007. The Crisis of Trust and Planning. Planning Theory and Practice. 8.2, p.229247.

Tait M. 2011. Trust and the Public Interest in the Micropolitics of Planning Practice. Journal of Planning Education and Research, 31.2, p.157-171.

Ward S. 2004. Planning and Urban Change. London: SAGE Publications Ltd. 